\title{
Media Comparison for Enumeration of Actinobacteria and their Catabolic Diversity in the Crop Rhizosphere of Arid, Semi-Arid and Humid Regions (AER 3 and AER 6) of India
}

\author{
T.K. Radha ${ }^{1 *}$, D.L.N. Rao ${ }^{2}$ and K.R. Sree Ramulu ${ }^{3}$ \\ ${ }^{1}$ Indian Institute of Horticulture Research, Bengaluru-560 089, Karnataka, India \\ ${ }^{2}$ Indian Institute of Soil Science, Nabi Bagh, Bhopal-462 038, Madhya Pradesh, India \\ ${ }^{3}$ Department of Agricultural Microbiology, University of Agricultural Sciences, GKVK, \\ Bengaluru-560065, Karnataka, India \\ *Corresponding author
}

A B S T R A C T

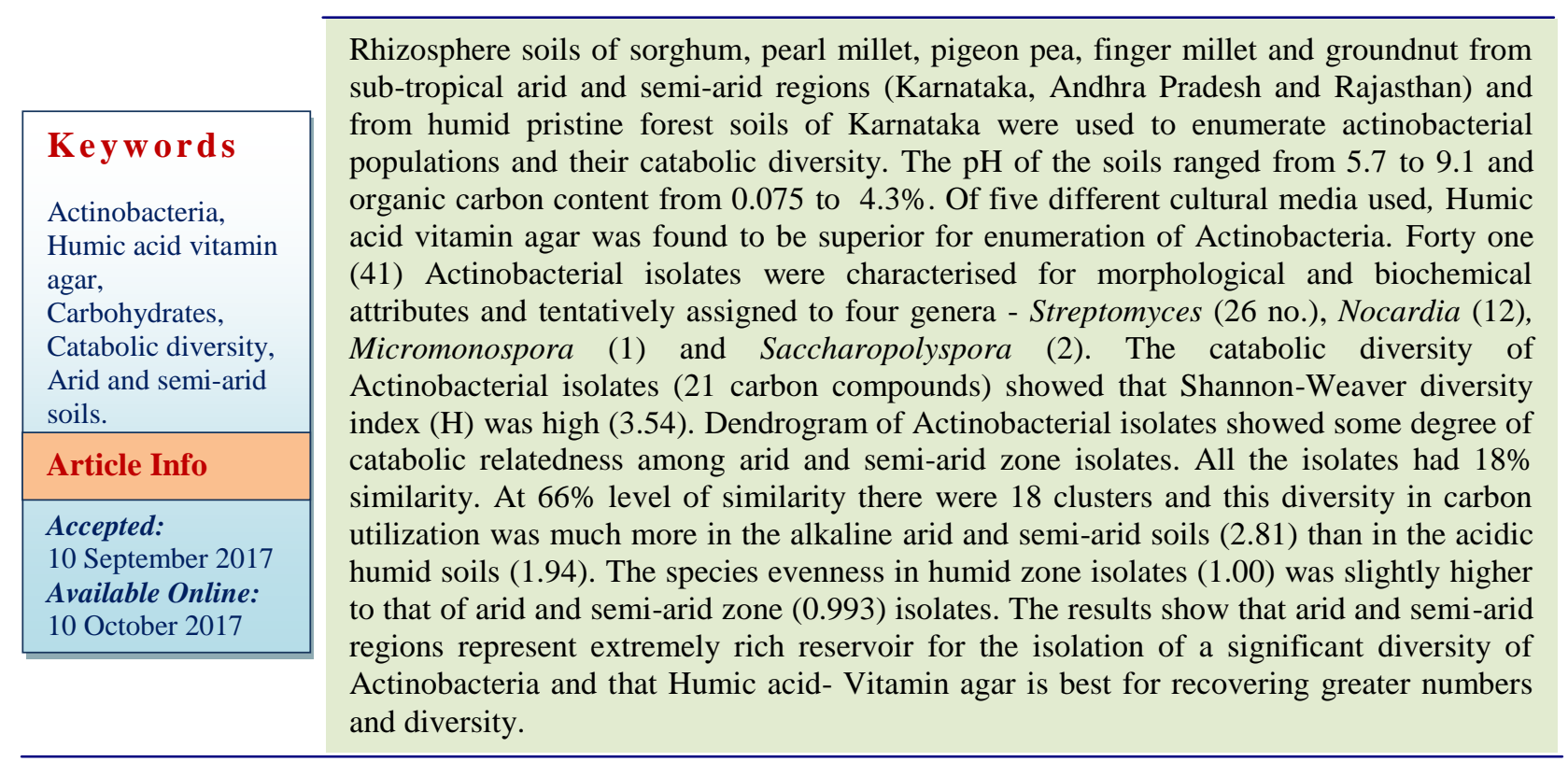

\section{Introduction}

Actinobacteria are the most widely distributed group of microorganisms and occur as saprophytes in soil (Takizawa et al., 1993). They are Gram-positive, prokaryotic microorganisms; their growth and proliferation in soil is influenced by number of factors such as soil type, organic matter content, salinity, relative moisture content, temperature and vegetation (Waksman, 1967). Most Actinobacteria in soil belong to the genus Streptomyces (Goodfellow and Simpson, 1987, Suzuki et al., 2000) and 60 per cent of the biologically active compounds such as antifungal and antibacterial compounds or plant growth promoting substances have originated from this genus 
(Ilic et al., 2007). Streptomyces and other Actinobacteria are major contributors to biological buffering of soils and play an important role in organic matter decomposition (Dhingra and Sinclair, 1995). They are able to produce spores, which help in dissemination and resistance to many adverse conditions (Goodfellow and Williams, 1983; Chater, 1993).

For isolation of soil Actinobacteria, selection of media is important for understanding their ecological properties and for discovery of novel strains which can produce useful bioactive secondary metabolites. Numerous media have been described for the isolation of Actinobacteria from soil and other natural materials. Use of isolation media with high carbon to nitrogen ratio and resistant complex carbon and nitrogen sources, e.g., starch, casein, chitin, humic acid etc., is suitable for isolation and enumeration of Actinobacteria (Gray and Williams, 1971). The increasing emergence of new diseases and pathogens, and the antibiotic resistance in recent years have caused an interest in searching for new biologically active compounds, thus the studies on distribution and diversity of Actinobacteria are crucial in discovering new strains and to explore ecological niches in different regions worldwide. The aim of this study was to compare different media for enumeration of Actinobacteria and to study the catabolic diversity of Actinobacteria in arid, semi-arid and humid regions of India.

\section{Materials and Methods}

\section{Soils}

Soil samples were collected from the rhizosphere of Sorghum (Sorghum vulgare), Pearl millet (Pennisetum typhoideum), Pigeon pea (Cajanus cajan), Finger millet (Eleusine coracana) and Groundnut (Arachis hypogea) grown in arid region of Jaisalmer in
Rajasthan; arid and semi-arid regions of Belgaum, Hubli, Bijapur and Tumkur districts of Karnataka and Anantapur in Andhra Pradesh. Two soil samples from pristine forest in humid region of Karnataka (Kegdal, Vibuthi). Soil samples were air dried and analyzed for their physico-chemical properties by standard procedures (Hesse, 1971).

Isolation and comparison of media for enumeration

Isolation of Actinobacteria was done by standard plate count methods after serial dilution of soils. Five different media were used for isolation and enumeration of Actinobacteria viz., actinomycetes isolation agar, starch casein agar, arginine glycerol salts medium, humic acid vitamin agar and Kuster's agar.

Forty one morphotypes were short listed and were characterized in detail for morphological and biochemical attributes using the Bergey's manual of determinative bacteriology $9^{\text {th }}$ edition (Holt et al., 1994). Morphologically distinct Actinobacterial isolates were selected on the basis of spore color, mycelia formation, pigment production and reverse side color formation (data not shown) and these isolates were tentatively assigned to four genera - Streptomyces (26 no.), Nocardia (12), Micromonospora (1) and Saccharopolyspora (2) and tested for utilization of different carbon compounds.

\section{Carbohydrates utilization}

Actinobacteria were tested for utilization of twenty one different carbon compounds like monosaccharides (adonitol, arabinose, dextrose, dulcitol, fructose, galactose, inositol, mannitol, mannose, rhamnose, sorbitol, xylose), disaccharides (cellobiose, lactose, maltose, melibiose, salicin, sucrose, 
trehalose), trisaccharides (raffinose) and polysaccharides (inulin) as per procedure of Shirling and Gottlieb (1966) using carbohydrate impregnated discs instead of sugar solutions.

Actinobacteria were inoculated into $50 \mathrm{ml}$ tryptone yeast extract broth in Erlenmeyer flasks and incubated for 48 hours at $28^{\circ} \mathrm{C}$ in an orbital shaker at $125 \mathrm{rpm}$. Sterile glass beads were added and subjected to vigorous agitation to break the mycelia. Homogenized culture was centrifuged at $8000 \mathrm{rpm}$ for 5 minutes to pelletize the culture. The supernatant was decanted and the culture was re-suspended in $1.5 \mathrm{ml}$ of sterile distilled water and centrifuged to pelletize the culture. The procedure was repeated 4-5 times. Finally the pellet was used for inoculating the plates. Approximately $50 \mu \mathrm{l}$ of washed inoculum (test culture) was placed on one edge of the phenol red agar medium and streaked across the Petri dish. The carbohydrate impregnated discs (25 mg carbohydrate/disc) were placed and pressed gently on the surface of the plate at sufficient distance $(2 \mathrm{~cm})$ from each other. Plates were incubated at $36 \pm 1.0^{\circ} \mathrm{C}$ for 48 hours and results were recorded, carbon utilization was visualized by change in colour around the disc from red to yellow.

\section{Diversity analysis}

The diversity of Actinobacteria based on carbon utilization was calculated by using the formula (Saeki et al., 2008).

$\mathrm{H}^{1}=-\Sigma^{\mathrm{s}}\left(\mathrm{P}_{\mathrm{i}} \ln \mathrm{P}_{\mathrm{i}}\right)$

$\mathrm{P}_{\mathrm{i}}=$ Fraction of individuals belonging to $\mathrm{i}^{\text {th }}$ species

$\mathrm{E}=\mathrm{H} / \mathrm{H}_{\max }$

Where, E=Evenness, $\mathrm{H}=$ diversity, $\mathrm{H}_{\max }=$ maximum diversity possible

\section{Cluster analysis of catabolic diversity}

The carbon utilization (21 sources) pattern of the Actinobacteria was used for cluster analysis. A binary matrix was constructed where 0 denotes inability and 1 denotes ability to catabolize a particular source. The data was analyzed using the SIMQUAL (Similarity for Qualitative data) of NTSYS(Numerical taxonomic and multivariate analysis system) PC2 package. The isolates were grouped as per Jaccard's similarity index by the unweighted paired group method using arithmetic means (UPGMA) and depicted as a dendrogram.

\section{Results and Discussion}

\section{Isolation and media comparison}

The $\mathrm{pH}$ of the soils varied from 5.7 to 9.1 in semi-arid and arid soils with organic carbon content of 0.075 to 0.70 . In the humid soils the $\mathrm{pH}$ averaged 6.0 while org $\mathrm{C}$ content was $2.9 \%$ (Table 1). Among the different media tested, higher population of Actinobacteria was recorded on Humic acid vitamin agar (29 $\mathrm{x} \quad 10^{4} \mathrm{cfu} / \mathrm{g}$ soil) while the lowest Actinobacterial population was recorded in argnine glycerol salts medium $\left(2.3 \times 10^{4} \mathrm{cfu} / \mathrm{g}\right.$ soil). Humic acid vitamin agar was the best medium for enumeration of Actinobacteria from most of the soils. These results are in conformity with Hayakawa and Nonomura (1987) who demonstrated the superiority of Humic acid vitamin (HV) agar over colloidal chitin agar, glycerol-arginine agar and starchcasein-nitrate agar, for the isolation and enumeration of soil Actinobacteria. Similarly, Coombs and Franco (2003) observed that the nutrient poor media such as HV agar, TWYE (Tap water yeast extract) and YECH (Yeast extract- casein hydrolysate) agar are most effective for isolation of endophytic actinobacteria from wheat roots. Organic media with low nutrient concentrations like WYE (water yeast extract) and CAYEG 
(casamino acids-yeast extract-glucose) agar were found best for isolating diverse Actinobacteria by avoiding contamination and overgrowth by eubacteria and fungi (Crawford et al., 1993). When the average counts of Actinobacteria obtained from different type of soils grown on five different media were compared, the highest Actinobacterial population was observed in rhizosphere soils of sorghum and pigeon pea in black soils which was twofold higher than that of red soils of sorghum, finger millet and groundnut which may be due to soil type (higher clay content and organic carbon) (Table 2).

Varalakshmi et al., (2010) also observed that black soils harboured more population of Actinobacteria in the rhizosphere of fox tail millet as compared to red soil. Actinobacteria make up 10-15 per cent of the total microbial population in both virgin and cultivated soils
(Alexander, 1961). In alkaline soils, especially when dry, the relative abundance is spectacularly high. However, in comparison with true bacteria, Actinobacteria are less common in wet than in dry soils. The population is likewise greater in grassland and pastured soil than in cultivated fields (Alexander, 1961). In this study, comparison of Actinobacterial population of forest soil (Kegdal forest, black soil) was made with adjacent cultivated soil (Koundal, Sorghum, black soil) and found that the Actinobacterial population was more in cultivated soils (by $37.5 \%$ ), even though the $\mathrm{pH}$ was almost similar (6.1-6.2) but the organic carbon was higher in forest soil $(3.60 \%)$ than in cultivated soils $(0.81 \%)$ (Table 1$)$. This may be due to the high wetness of forest soil (virgin) as compared to the cultivated sorghum soil. The findings of the study supports the similar observation made earlier by Alexander (1961).

Table.1 Details of crop, location and physico-chemical properties of collected soil samples

\begin{tabular}{|c|c|c|c|c|c|c|}
\hline Soil sample no & Crop & Type of soil & Place & District and State & pH & $\begin{array}{c}\text { Org. C } \\
(\%)\end{array}$ \\
\hline 1 & Forest & Pristine(Black) & Kegdal & $\begin{array}{c}\text { Uttarakannada, } \\
\text { Karnataka }\end{array}$ & 6.1 & 3.60 \\
\hline 2 & Forest & Pristine(Laterite) & Vibuthi & $\begin{array}{c}\text { Uttarakannada, } \\
\text { Karnataka }\end{array}$ & 5.9 & 4.30 \\
\hline 3 & Sorghum & Hilly(Black) & Koundal & $\begin{array}{c}\text { Belgaum, } \\
\text { Karnataka }\end{array}$ & 6.2 & 0.81 \\
\hline 4 & Sorghum & Plains(Black) & Hubli & Hubli, Karnataka & 8.1 & 0.66 \\
\hline 5 & Pigeon pea & Plains(Black) & Honaganahalli & Bijapur, Karnataka & 9.0 & 0.70 \\
\hline 6 & Pearl millet & Plains(Black) & $\begin{array}{c}\text { Honaganahalli } \\
\text { railway gate }\end{array}$ & $\begin{array}{c}\text { Bijapur, Karnataka } \\
8.7\end{array}$ & 0.63 \\
\hline 7 & Sorghum & Plains(Red) & Timmapur & Gadag, Karnataka & 8.4 & 0.65 \\
\hline 8 & Finger & Plains(Red) & Ballenahalli & Tumkur, Karnataka & 5.7 & 0.46 \\
\hline 10 & Groundnut & Plains(Red) & Anantapur & $\begin{array}{c}\text { Anantapur, } \\
\text { Andhrapradesh }\end{array}$ & 7.0 & 0.27 \\
\hline 11 & Pearl millet & $\begin{array}{c}\text { Desert(loamy } \\
\text { sand) }\end{array}$ & Jaisalmer & $\begin{array}{c}\text { Jaisalmer, } \\
\text { Rajasthan }\end{array}$ & 9.1 & 0.17 \\
\hline
\end{tabular}


Table.2 Enumeration of Actinobacteria (No. X $10^{4} \mathrm{cfu} / \mathrm{g}$ soil) in different growth media

\begin{tabular}{|l|c|c|c|c|c|c|}
\hline \multicolumn{1}{|c|}{ Location } & Crop & AIA & SCA & HVA & AGS & KA \\
\hline Kegdal (Karnataka) & Forest soil & 8.5 & 8.0 & 14.7 & 3.1 & 8.6 \\
\hline Vibuthi (Karnataka) & Forest soil & 7.5 & 7.2 & 9.0 & 3.0 & 6.7 \\
\hline Koundal (Karnataka) & Sorghum & 8.0 & 7.5 & 27.7 & 4.0 & 11.8 \\
\hline Hubli (Karnataka) & Sorghum & 8.8 & 7.3 & 28.0 & 4.2 & 12.1 \\
\hline Honaganahalli (Karnataka) & Pigeon pea & 9.0 & 7.7 & 29.0 & 5.0 & 12.7 \\
\hline Honaganahallirailway gate (Karnataka) & Pearl millet & 7.8 & 6.7 & 16.2 & 3.3 & 8.5 \\
\hline Timmapur (Karnataka) & Sorghum & 5.2 & 4.6 & 10.0 & 2.8 & 5.7 \\
\hline Ballenahalli (Karnataka) & Finger millet & 5.5 & 4.1 & 10.5 & 2.3 & 5.6 \\
\hline Anantapur(Andhra Pradesh) & Groundnut & 5.0 & 5.0 & 12.2 & 2.9 & 6.3 \\
\hline Jaisalmer (Rajasthan) & Pearl millet & 7.8 & 7.0 & 6.4 & 6.0 & 6.8 \\
\hline Sam (Rajasthan) & Desert soil & 5.6 & 5.7 & 5.2 & 4.0 & 5.1 \\
\hline Average counts (Population) & & 7.15 & 6.44 & 15.35 & 3.69 & 8.2 \\
\hline S.Em \pm & & 0.04 & 0.02 & 0.02 & 0.01 & 0.05 \\
\hline CD @ 1\% & & 0.14 & 0.08 & 0.06 & 0.04 & 0.18 \\
\hline
\end{tabular}

*AIA: Actinomycetes Isolation Agar, SCA: starch Casein Agar, HVA: Humic acid Vitamin Agar, AGS: Arginine Glycerol Salts medium, KA: Kuster's agar

Table.3 Shannon diversity index and evenness of Actinobacterial isolates

\begin{tabular}{|c|c|c|c|}
\hline Climatic region & No. of isolates & $\begin{array}{c}\text { Shannon and Weaver } \\
\text { diversity index }(\mathbf{H})\end{array}$ & $\begin{array}{c}\text { Evenness (E) of } \\
\text { the species }\end{array}$ \\
\hline Arid & 18 & 2.81 & 0.993 \\
\hline Semi-arid & 16 & 2.81 & 0.993 \\
\hline Humid & 7 & 1.94 & 1.000 \\
\hline All & 41 & 3.54 & 0.982 \\
\hline
\end{tabular}

Fig.1 Carbohydrates utilization by Actinobacterial isolates

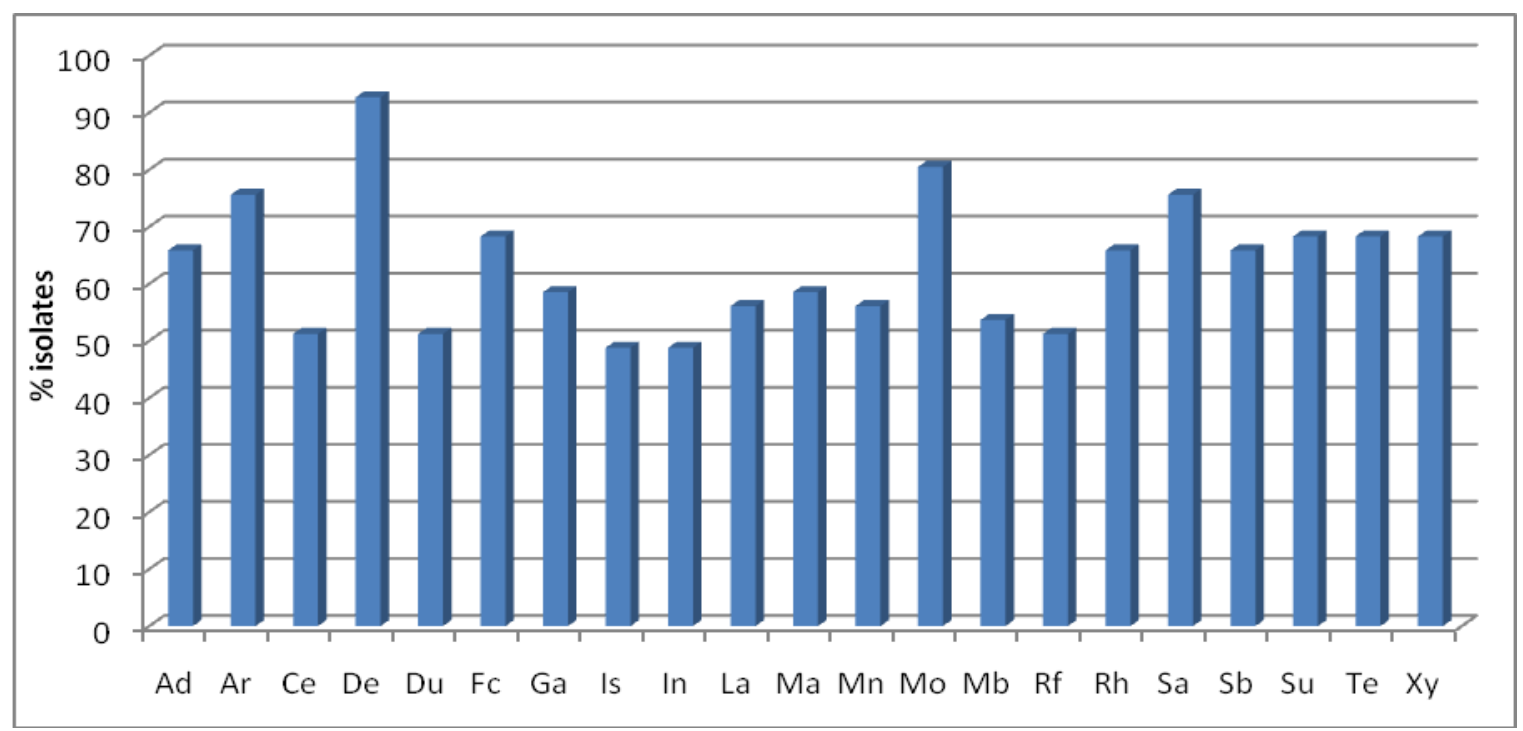

Ad: adonitol, Ar: arabinose, Ce: cellobiose, De: dextrose, Du: dulcitol, Fc: fructose, Ga: galactose, Is: inositol, In: inulin, La: lactose, Ma: maltose, Mn: mannitol, Mo: mannose, Mb: melibiose, Rf: raffinose, Rh: rhamnose, Sa: salicin, Sb sorbitol, Su: sucrose, Te:trehalose, Xy: xylose 


\section{Int.J.Curr.Microbiol.App.Sci (2017) 6(10): 955-962}

Fig.2 Dendrogram of Actinobacterial isolates (41) based on carbohydrate utilization (\% similarity)

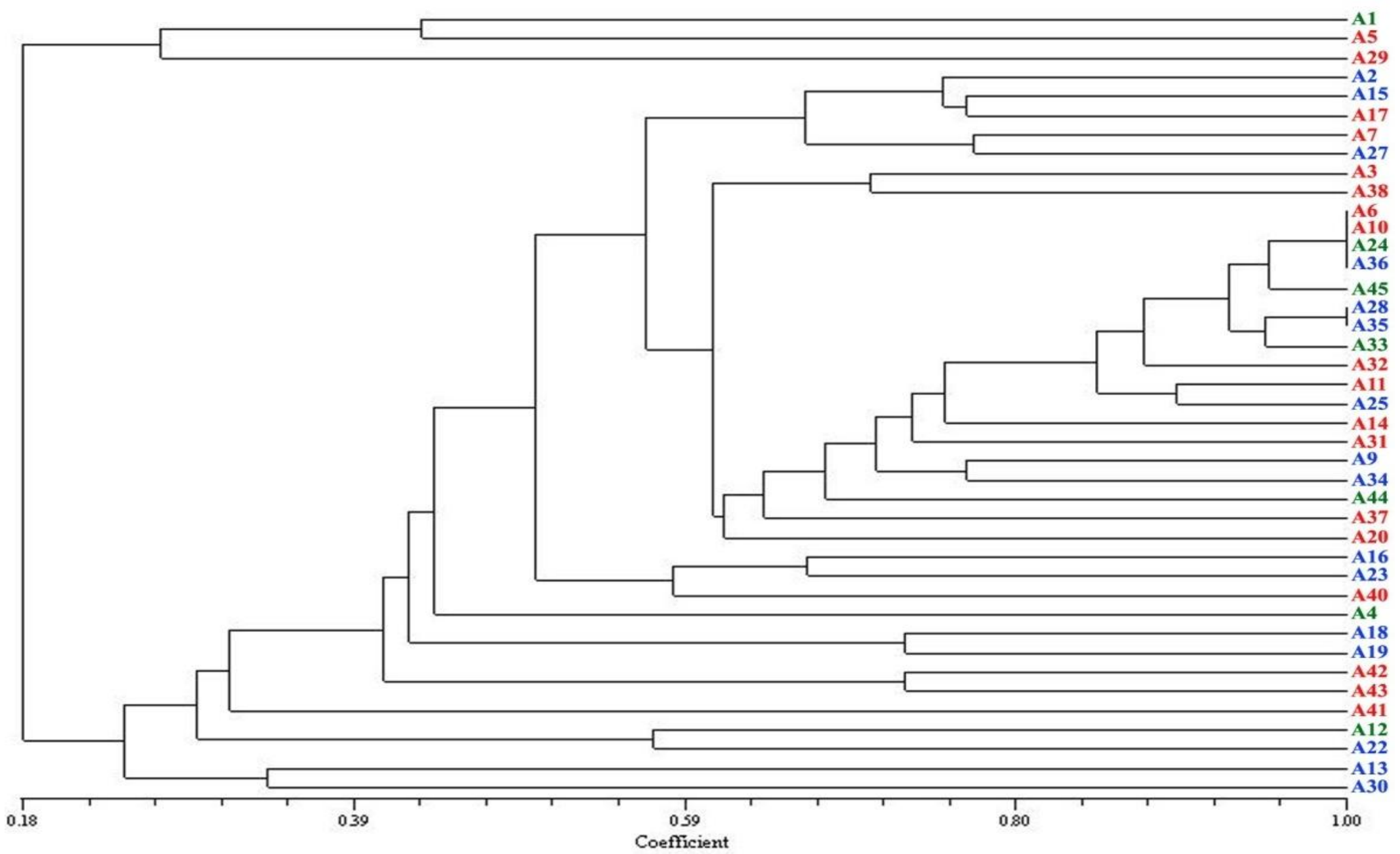

A1: Streptomyces, A5: Streptomyces, A29: Nocardia, A2: Streptomyces, A15: Streptomyces, A17: Streptomyces, A7: Streptomyces, A27: Streptomyces, A3: Streptomyces, A38: Streptomyces, A6: Streptomyces, A10: Streptomyces, A24: Nocardia, A36: Streptomyces, A45: Streptomyces, A28: Nocardia, A35; Nocardia, A33: Nocardia, A32: Streptomyces, A11: Streptomyces, A25: Nocardia, A14: Streptomyces, A31: Nocardia, A9: Streptomyces, A34: Nocardia, A44: Streptomyces, A37: Nocardia, A20: Micromonospora, A16: Streptomyces, A23: Nocardia, A40: Streptomyces, A4: Saccharopolyspora, A18: Streptomyces, A19: Streptomyces, A42: Streptomyces, A43: Nocardia, A41: Saccharopolyspora, A12: Streptomyces, A22: Nocardia, A13: Streptomyces, A30: Streptomyces 


\section{Carbohydrates utilization}

Actinobacteria are heterotrophs and utilize a variety of carbon sources ranging from simple (organic acids and sugars) to highly complex molecules (polysaccharides, lipids, proteins and aliphatic hydrocarbons). Cellulose is decomposed by many Actinobacterial species. It is also reported that many strains are capable of degrading starch, inulin and chitin (Alexander 1961). Chitin hydrolysis is especially characteristic of Actinobacteria. The metabolism of unusual organic molecules such as paraffins, phenols, steroids and pyrimidines is well documented for Nocardia spp. whereas Micromonospora strains decompose chitin, cellulose, glucosides, pentosans and possibly lignin.

In this study all the 21 carbon sources were utilized by one or the other Actinobacterial isolates. The highest number of isolates utilized monosaccharides followed by disaccharides, trisaccharides and polysaccharides. The best carbon source was found to be dextrose which was utilized by maximum number of isolates $(90 \%)$ followed by mannose $(80 \%)$ and arabinose $(75 \%)$. The least used carbon sources were inositol and inulin (49\%) (Fig. 1). These results indicate that Actinobacteria are highly non-specific, in their carbon requirements. Strzelczyk and Pokojska-Burdziej (1984) also reported the non-specificity of Actinobacteria for carbon requirements.

\section{Shannon diversity index and cluster analysis}

Bsed on the utilization of 21 carbon sources the Shannon-Weaver diversity index $(\mathrm{H})$ of the Actinobacteria in arid and semi-arid soils is 2.81 and the species evenness is 0.993 . In humid soil, the diversity is lesser (1.94) but species are more evenly distributed (1.000) (Table 3).
The dendrogram of Actinobacterial isolates showed that they were quite diverse in their utilization of carbohydrates. All the Actinobacterial isolates had only 18 per cent level of similarity. The isolates were thus very diverse and had lot of differences in carbon utilization (Diversity index $\mathrm{H}=3.54$ ). The high extent of diversity was also apparent from the high number of clusters (6 clusters at 33 per cent, 11 clusters at 50 per cent and 18 clusters at $66 \%$ level of similarity, Fig. 2). There was one mega cluster (cluster 6 with 20 isolates) which had most of the isolates having representation of all the three regions. Cluster 7 had 5 isolates belonging to arid and semiarid regions. All other clusters had 2 or 3 isolates. The data showed that isolates from arid and semi-arid regions were more diverse $(\mathrm{H}=2.81)$ compared to humid region $(\mathrm{H}=$ 1.94). Higher diversity in arid and semi-arid regions can be attributed to soil diversity, host crop and the ecological niche (drought stress and low substrate availability) which resulted in greater speciation (Odum et al., 1971). The higher acidity of forest soils $(\mathrm{pH} \sim 6.0)$ probably contributed to the lower diversity compared to arid and semi-arid soils $(\mathrm{pH}$ ranged from 7.0-9.1). Thus the results from our study confirm that both arid and semi-arid regions represent extremely rich reservoir for the isolation of a significant diversity of Actinobacteria.

\section{References}

Alexander, M., 1961. Introduction to Soil Microbiology, Wiley International Edition, Tropan Company Ltd., Japan, pp 472.

Chater, K.F., 1993. Genetics of differentiation in Streptomyces. Ann. Rev.Microbiol., 47:685-713.

Coombs, J. T., and Franco, C. M. 2003. Isolation and identification of Actinobacteria from surface-sterilized wheat roots. Appl.Environ. 
Microbiol., 69(9): 5603-5608.

Crawford, D. L., Lynch, J. M. Whipps, J. M. and Ousley, M. A. 1993. Isolation and characterization of actinomycete antagonists of a fungal root pathogen. Appl. Environ. Microbiol, 59(11): 38993905.

Dhingra, O.D., and Sinclair, J.B. 1995. In: Basic plant pathology methods. CRC Press: USA.

Goodfellow, M., and Simpson, K.E. 1987. Ecology of Streptomycetes. Front. Appl.Microbiol, 2: 97-125.

Goodfellow, M., and Williams, S.T. 1983. Ecology of actinomycetes. Annu. Rev. Microbiol., 37:189-216.

Gray, T.R.G., and Williams, S.T. 1971. Soil micro-organisms (Vol. 2). Edinburgh: Oliver and Boyd.

Hayakawa, M., and Nonomura, H. 1987. Humic acid-vitamin agar, a new medium for the selective isolation of soil actinomycetes. J. Ferment. Technol., 65: 501-509.

Hesse, P. R., 1971. "A Text Book of Soil Chemistry Analysis." John Murray Ltd. London. 412: 120-309.

Holt, J.G., Krirg, N.R. Sneath, P.H. Standley, J.T. Williams, S.T. 1994. Bergey's manual of determinative bacteriology, 9th edn, Williams and Wilkins, Baltimore, USA.

Ilic, S.B., Konstantinovic, S.S. Todorovic, Z.B. Lazic, M.L.Veljkovic, V.B. Jokovic, N. and Radovanovic, B.C. 2007. Characterization and antimicrobial activity of the bioactive metabolites in Streptomycete isolates. Microbiol, 76: 421-428.
Odum, E. P., Odum, H. T. and Andrews, J. 1971. Fundamentals of ecology., Vol. (3). Philadelphia, Saunders.

Saeki, Y., Minami, M. Yamamoto, A. Akao, S. 2008. Estimation of the bacterial community diversity of soybean- nodulating bradyrhizobia isolated from $\mathrm{Rj}$ - genotype soybeans. Soil Sci., \& Plant Nutrn, 54.5: 718-724.

Shirling, E.G., and Gottlieb, D. 1966. Methods for characterization of Streptomyces species. Int. J. Syst. Bacteriol., 16:313-340.

Strzelczyk, E., and Pokojska-Bucrdziej, A. 1984. Production of auxins and gibberellin-like substances by mycorrhizal fungi, bacteria and actinomycetes isolated from soil and the mycorrhizosphere of pine (Pinussilvestris L.). Plant Soil, 81(2): 185-194.

Suzuki, S. I., Yamamoto, K. Okuda, T. Nishio, M. Nakanishi, N. and Komatsubara, S. 2000. Selective isolation and distribution of Actinomadura rugatobispora strains in soil Actinomycetol, 14:27-33.

Takizawa, M., Colwell, R. R. and Hill, T. R. 1993. Isolation and Diversity of Actinomycetes in the Chesapeake Bay. Appl. Environ. Microbiol, 59: 997-1002. Varalakshmi, T., Sekhar, K. M. Rafi, M. M. and Charyulu, P. B. B. N. 2010. Population studies of actinomycetes isolated from the rhizosphere of Foxtail millet. Curr.Biotica, 3(1):305-317.

Waksman, S. A., 1967. The Actinomycetes. A summary of current knowledge.

\section{How to cite this article:}

Radha, T.K., D.L.N. Rao and Sree Ramulu, K.R. 2017. Media Comparison for Enumeration of Actinobacteria and their Catabolic Diversity in the Crop Rhizosphere of Arid, Semi-Arid and Humid Regions (AER 3 and AER 6) of India. Int.J.Curr.Microbiol.App.Sci. 6(10): 955-962. doi: https://doi.org/10.20546/ijcmas.2017.610.115 